\title{
Cervantes y la revolución cultural del renacimiento: Acteón y don Quijote
}

\author{
BIENVENIDO MORROS*
}

El Barroco no olvidó los mitos de Occidente, de los que se apropió con los valores y símbolos que ya habían tenido en el Renacimiento o incluso en la Edad Media. Por eso produjo dos manuales sobre el tema, con abundante información al respecto: la Philosophía secreta de la gentilidad (Madrid, 1585), del bachiller Juan Pérez de Moya, y el Teatro de los dioses de la gentilidad, en dos partes, una primera (Salamanca, 1620) y otra segunda (1623), del padre Baltasar de Vitoria. Además siguió traduciendo al castellano las Metamorfosis de Ovidio, casi siempre acompañadas con los comentarios de rigor: Jorge de Bustamante (s. 1., h. 1543), Antonio Pérez Sigler (Salamanca, 1580), Felipe Mey (Tarragona, 1586) y Pedro Sánchez de Viana (Valladolid, 1589). ${ }^{1}$

Cervantes no fue demasiado amigo ni de mitos ni de moralizaciones, y cuando introdujo alguno en su obra se decantó por la explicación más novedosa y actual. En el Quijote, por ejemplo, pone en boca del hidalgo manchego una comparación con Acteón, y en principio se diría que el símil no deja de ser un tanto gratuito y erudito, pero, estudiando con detalle la escena, nos damos cuenta de que es más importante de lo que a primera vista parece.

Tras una prolongada estancia en el castillo de los duques, don Quijote decide marcharse para "salir de tanta ociosidad": en principio piensa dirigirse a Zaragoza, aunque después cambiará de opinión. Primero halla a unos labradores que llevan envueltas en unas sábanas las imágenes de diversos caballeros santos (san Jorge, san Martín, Santiago, etc), y al poco, tras adentrarse "en

* Universidad Autónoma de Barcelona

1. Para las traducciones de Ovidio en el Renacimiento aún sigue siendo básico el trabajo de ScHEVILL, Rudolf, Ovid ant the Renascence in Spain, Berkeley, University of California Press, 1913. 
una selva que fuera del camino estaba", queda atrapado en unas redes tendidas entre los árboles de un lado y del otro. Intenta romperlas pero desiste de ello al ver asomar en seguida a dos hermosas mozas disfrazadas de pastoras que, según confiesan, se están preparando para representar una égloga de Garcilaso y otra de Camoes. Ante tan súbita e inesperada aparición el hidalgo manchego reconoce sentirse tan perplejo como Acteón cuando sorprendió a Diana bañándose junto a sus ninfas:

Por cierto, hermosísima señora, que no debió quedar más suspenso ni admirado Anteón cuando vio al improviso bañarse en las aguas a Diana, como yo he quedado atónito en ver vuestra belleza. ${ }^{2}$

Las zagalas lo han invitado a conocer al resto de acompañantes, todos hidalgos y vecinos de una aldea "de hasta dos leguas" del lugar en el que se encuentran, y don Quijote no puede menos que agradecer tanta hospitalidad, hasta el punto de improvisar un discurso sobre la ingratitud cuando se ha sentado a comer en la mesa preparada en el interior de una de las tiendas:

Entre los pecados mayores que los hombres cometen, aunque algunos dicen que es la soberbia, yo digo que es el desagradecimiento, ateniéndome a lo que suele decirse: que de los desagradecidos está lleno el infierno. Este pecado, en cuanto me ha sido posible, he procurado yo huir desde el instante que tuve uso de razón... (1103).

Desde la tardía antigüedad ya los primeros mitógrafos reconocieron en el trágico final de Acteón una enseñanza sobre los peligros que comporta la dedicación en exclusiva a la caza. ${ }^{3}$ Ésa es una moraleja que se ha repetido hasta la saciedad en casi todos los libros en que se menciona al príncipe de Tebas. Juan Pérez de Moya y Baltasar de Vitoria la reproducen en sus respectivos manuales, y sólo se había atrevido a contradecirla, mucho antes, Natale Conti en el suyo, titulado Mytologiae sive explicationum fabularum libri decem (Venecia, 1551), en que considera absurdo seguir interpretando la muerte de Acteón por sus propios perros como la disipación de sus propiedades a causa de la caza:

Fuerunt qui putarint Actaeonis facultates per canum rabiem aut per iratam venationum deam insulse dissipatas significari, quia canes non

2. Rico, Francisco, dir., Don Quijote de la Mancha, Instituto Cervantes-Crítica, Barcelona, 1998, p. 1102; en el presente trabajo una cifra en números árabes después de una cita de la obra remite a las páginas de esta edición.

3. Para aspectos en general del mito de Acteón, véanse Heath, John, Actaeon, the Unmannerly Intruder. The Myth and his Meaning in Classical Literature, Lang, New York, 1992; y HERNÁNDEZ DE LA FUENTE, David, "Versiones, interpretaciones e imágenes del mito de Acteón”, Studium, VIII-IX (2001-2002), pp. 227-259.

ANALES CERVANTINOS, VOL. XXXVII, PP. 167-177, 2005. ISSN: 0569-9878 
Actaeonem, sed eius opes laniauerint quod quidem perridiculum mihi videtur

('Hubo quienes creyeron que por la rabia de los perros o por la airada diosa de la caza se ha de entender las provisiones de Acteón neciamente disipadas, porque los perros no despedazaron a Acteón, sino despedazaron sus riquezas, lo que sin duda me parece muy ridículo'). ${ }^{4}$

A cambio Conti propone una nueva explicación, que consiste en identificar a los perros del príncipe tebano con los ingratos que olvidan los beneficios recibidos de su señor:

Per hanc igitur fabula nos ab beneficia in viros bonos conferenda adhortabantur ac retrahebant a benemerendo de ingratiis \& immemoribus acceptorum hominibus... Omnium sane beneficiorum optimum est illud quod apud virum bonum \& memorem \& gratum collocatur, quod vero in maleficum \& ingratum collatum est, omnino male collatum fuit: quippe cum improbi homines, ne parem gratiam referre cogantur, saepius pro acceptis beneficiis simultatis causas aucupentur, seque vel quavis levissima de causa iratos fingant, ut sic deletum appareat quidquid in eos collatum sit. Ut prudentiores igitur essemus in conferendis beneficiis, ne honori, facultatibus, vitaeque nostrae insidiatores nostris sumptibus aleremus, rationem conferendorum beneficiorum nos antiqui docuerunt, quippe cum beneficium viro bono facere, sit prope accipere, atque haec nonnulla pars est iustitiae ut traditum est in officiis (fol. 442).

('Por esta fábula, pues, nos exhortaban a dispensar beneficios a los hombres buenos y nos alejaban muy merecidamente de los hombres ingratos y olvidadizos de las cosas recibidas. El mejor de todos los beneficios, en verdad, es el que se da a los hombres buenos, con memoria y agradecidos, pero el que se dispensa al malvado y al desagradecido se dispensa mal en todas las maneras, puesto que los hombres malvados, para no obligarse a restituir un favor parecido, a menudo, en lugar de los beneficios recibidos, urden causas de enemistad, o se fingen enojados por cualquier motivo insignificante, para que aparezca borrado todo lo que se les haya concedido. Para que seamos, pues, más prudentes en la concesión de beneficios los antiguos nos enseñaron el medio de concederlos, para que no alimentemos a los traidores de nuestra vida, que nos arrebatan el honor y nuestras propiedades, puesto que hacer un beneficio a un hombre bueno es casi recibirlo, y ésta es una parte de la justicia, como se nos enseña en los deberes')

En la tradición castellana, Pedro Sánchez de Viana cita esta última interpretación junto a la más tradicional, que toma literalmente de las glosas en

4. Cito por la edición de Venecia, 1581, fol. 442; existe una traducción al castellano por MoNTIEL, Rosa María, y Álvarez Morán, María Consuelo, Universidad de Murcia, Murcia, 1988, p. 477.

ANALES CERVANTINOS, VOL. XXXVII, PP. 167-177, 2005. ISSN: 0569-9878 
prosa que Juan de Mena compuso para La coronación del marqués de Santillana; en esa fuente también se había inspirado Juan Pérez de Moya. Vale la pena, pues, leer los tres testimonios para comprobar qué interpretaciones descarta Cervantes y cuáles asume:

Por Acteón podemos entender cualquier homne de grande estado e manera así como era este infante, el cual, en lugar de se dar a prender buenas costumbres por que fuese a[p]to e meresçedor de administrar tan alto estado como el de la caballería, dase a la caza distribuyendo todo cuanto tiene en perros e en canes non procurando la honor e acreçentamiento de la república nin pugna por la defender. Este atal es comido e disipado de sus canes, ca lo echan a mal, e aquellos aparejos de la caza le gastan e le comen lo que tiene que es mantenimiento de su vida, por lo que dice la fabla que este tal vino a do se estaba Diana bañando. Por Diana podemos entender la cobdicia de la caza, que trae a los tales en medio de las fiestas desfaciendo e menoscabando sus honras, por lo que dice la fabla que Diana paresçía más alta que las otras desde los hombros arriba, e por esto podemos entender -en cuanto Diana era deesa de la castidad-que la virtud de la castidad es más alta virtud que las otras e sobrepuja a las otras en exçelencia e en merescimiento de mayor galardón (Juan de Mena). ${ }^{5}$

Por Acteón podemos entender cualquiera hombre de grande estado, que en lugar de darse a aprender buenas costumbres para hacerse apto de administrar bien su república se da a la caza, destribuyendo cuanto tiene en perros y aves, no procurando el honor y acrecentamiento de la república, ni pugnando por la defender; este tal es comido y disipado de sus canes, porque lo echan a perder; y aquellos aparejos de la caza gastan y le comen lo que tiene, que es mantenimiento de su vida. Por lo cual dice la fábula que este tal vino donde estaba Diana bañándose. Por Diana podemos entender la codicia de la caza que los trae a los tales en medio de las fiestas, deshaciendo y menoscabando sus fuerzas y sus vidas. Que Diana paresciese más alta que las otras desde los hombros arriba, podemos entender (en cuanto Diana era deesa de la castidad) que la castidad es más alta que todas las otras, y las sobrepuja en excelencia y en merecimiento de mayor galardón (Juan Pérez de Moya). ${ }^{6}$

Y, moralizando esta fábula, [Juan de Mena] dice que por Acteón podemos entender cualquiera hombre de gran estado y autoridad, que, en lugar de darse al estudio de las letras y buenas costumbres para satisfacer al ministerio en que Dios le puso, se embebe en cazar, gastando en esto sus

5. Juan de Mena, Obras completas, ed. Pérez Priego, Miguel Ángel, Planeta, Barcelona, 1989, pp. $129-130$

6. Juan PÉRez DE MoyA, Philosofía secreta, ed. Claverïa, Carlos, Cátedra, Madrid, 1995, pp. 578579.

ANALES CERVANTINOS, VOL. XXXVII, PP. 167-177, 2005. ISSN: 0569-9878 
aparatos, los tesoros debidos antes a sus pobres vasallos. Estos tales se pueden justamente decir comidos de perros, pues menosprecian la obligación que tienen, y se dejan en la fama y reputación comer de murmuradores por haber gastado la vida y hacienda con perros y cazas. Natal Comité dice que todas las buenas obras que el hombre hace es bien empleada la que cae en el bien agradescido y perdida la que se hace al ingrato, porque 1[o]s tales, para desobligarse de la merced recibida, ordinariamente buscan ocasiones de enemistad con quien se la hizo, y fíngense enojados para que quede borrado el beneficio que rescibieron. Pues para enseñarnos los antiguos a ser prudentes en hacer buenas obras, escogiendo para ellas a hombres gratos, y no a traydores, fingieron esta fábula de Acteón hecho pedazos con los dientes de aquellos a quien él sustentó y regaló (Pedro Sánchez de Viana). ${ }^{7}$

En el Barroco lo normal fue ver en las desventuras del príncipe tebano los perjuicios causados por una afición desmedida a la caza, y, así, dramaturgos como Francisco de Rojas o Calderón de la Barca tuvieron muy presente esa interpretación del mito al componer, respectivamente, las comedias Del rey abajo, ninguno y El médico de su honra, de suerte que la moraleja de la fábula lo es también de esas dos obras. Francisco de Rojas, por ejemplo, casi en el centro geométrico de su obra, introduce un diálogo, mientras los dos personajes citados se hallan en el bosque practicando el arte venatorio, entre Blanca, Gerardo, Bras y Teresa; el porquero Bras, representante del gracioso, pregunta a sus acompañantes por el vicio "más caro... que hay en el mundo" (13331334), y el anciano Gerardo, símbolo de la sabiduría, responde que la caza, recordando precisamente las moralejas sobre nuestra fábula:

Que el hombre de caza, amigo,

tiene el de más perdición,

más costoso y infelice;

la moralidad lo dice

del suceso de Anteón (vv. 1340-1344). ${ }^{8}$

En otro pasaje del Quijote, Cervantes también arremete contra el arte venatorio, y lo hace por boca de Sancho, cuando él y su amo participan en una cacería de montería organizada por los duques al poco de llegar a su castillo. $\mathrm{Al}$ ver aparecer el primer jabalí el escudero abandona a su rucio y sale corriendo hasta alcanzar una encina de la que acaba colgado casi a ras de suelo. Ya a salvo Sancho no puede menos que censurar un ejercicio que cree demasiado peligroso y recordar el trágico final del rey astur Favila, que acabó devorado por un oso:

7. Anotaciones sobre los quince libros de las Transformaciones de Ovidio, fol. 70.

8. Francisco de Rosas, Del rey abajo ninguno, ed. Ruiz Morcuende, Federico, Madrid, EspasaCalpe, 1943, p. 55. 
Yo no sé qué gusto se recibe de esperar a un animal que, si os alcanza con un colmillo, os puede quitar la vida. Yo me acuerdo haber oído cantar un romance antiguo que dice:

De los osos sea comido

Como Favila el nombrado.

Eso es lo que digo..., que no querría yo que los príncipes y los reyes se pusiesen en semejante peligro, a trueco de un gusto que parece que no le había de ser, pues consiste en matar a un animal que no ha cometido delito alguno... Mía fe, señor, la caza y los pasatiempos más han de ser para los holgazanes que para los gobernadores (915).

Nuestro novelista, cuando podía sacar a colación la fábula de Acteón, la evita, y eso seguramente porque no desea relacionarla con la moraleja que se le atribuía en los Ovidios moralizados de la Edad Media. Por las mismas razones un siglo antes Erasmo había obrado con idéntico escrúpulo en su Stultitiae laus, al situar a los cazadores dentro de la misma categoría que la de los maridos consentidos y permisivos con sus mujeres, porque unos y otros se obstinan en la alabanza de algo que no la merece:

Ad hunc ordinem pertinent et isti, qui prae venatu ferarum omnia contemnunt, atque incredibilem animi voluptatem percipere se praedicant, quoties foedum illum cornuum cantum audierint, quoties canum ejulatus 9

('A esta clase pertenecen quienes desprecian todas las cosas por la caza de las fieras, e incluso proclaman experimentar un increíble placer del alma siempre que oyen aquel feo sonido de las trompas o el aullido de los perros');

sin aducir para nada a Acteón, describe el proceso de degradación al que llegan los cazadores, quienes, por su actividad, creen estar imitando a los reyes, cuando en realidad se convierten en sus propias presas:

Porro cui contigerit e bellua nonnihil gustare, is vero existimat, sibi non parum nobilitatis accedere. Itaque cum isti assidua ferarum insectatione atque nihil aliud assequantur, nisi ut ipsi propemodum in feras degenerent, tamen interea regiam vitam agere se putant (p. 196)

('Ahora bien: si alguno consigue apenas gustar de la bestia, ya estima sin embargo haber adquirido no poco de nobleza. Así, con la asidua persecución y deglución de las fieras, éstos no consiguen otra cosa que degradarse, casi como las propias fieras, y entretanto consideran llevar una vida regia').

9. Erasmo de Rotterdam, Stultitiae laus, ed. Nortes Valls, Oliveri, Barcelona, Bosch, pp. 194-197.

ANALES CERVANTINOS, VOL. XXXVII, PP. 167-177, 2005. ISSN: 0569-9878 
Por todo ello Cervantes ha creído oportuno poner en boca de su protagonista, don Quijote, un discurso sobre el pecado de la ingratitud después de dejarle compararse con Acteón, y a partir de ahí ha querido, al menos para las escenas inmediatas, hacerlo precisamente víctima de ese pecado.

Para mostrar su agradecimiento a las pastoras de marras, el hidalgo manchego se propone defender por la fuerza de las armas que ellas dos exceden en hermosura a todas las demás: se dirige al camino real para prohibir el paso a quienes tuvieran la intención de franquearlo si antes no reconocían lo que les pedía. En esa situación ve llegar una gran manada de toros conducidos por varios vaqueros, y en lugar de apartarse increpa a los animales, a los que ya no confunde con ningún tipo de ejército, para que admitan lo que acaba de hacer público. Lejos de detenerse los toros pasan "sobre don Quijote, y sobre Sancho, Rocinante y el rucio, dando con todos ellos en tierra" (1106); el hidalgo manchego se levanta y empieza a correr tras la manada, pero, al ver que no puede darle alcance, espera en pie la llegada de Sancho para montar en Rocinante y marcharse sin despedirse de las pastoras ni de sus acompañantes. En este episodio don Quijote, de alguna manera, ha padecido la ingratitud de sus huéspedes: para empezar ellos, nada más atisbar la manada, se dan la vuelta y se alejan del camino sin avisar al caballero andante, a quien tampoco socorren cuando lo han visto arrollado por los toros.

Molidos como están, caballero y escudero no tardan en detenerse en un prado con fuente para refrescarse y recuperarse de los golpes recibidos. Al atardecer llegan a una venta en la que por la noche, en la habitación contigua, el hidalgo manchego oye hablar de la segunda parte del Quijote de Avellaneda. Tras dialogar con quienes leen el libro se da cuenta de las mentiras que sobre él y su escudero introduce el apócrifo. Por ese motivo, al comprobar que su homónimo había participado en unas justas en Zaragoza, decide cambiar su destino por el de Barcelona. Tampoco parece muy descabellado pensar en algún tipo de ingratitud por parte de Avellaneda hacia nuestro personaje.

Después de abandonar la venta, señor y mozo cabalgan durante seis días sin protagonizar episodio digno de remarcarse. Al séptimo día llegan a un pequeño bosque de encinas o alcornoques, que no lo aclara el narrador, donde deciden pasar la noche. Sancho se duerme en seguida, pero don Quijote no puede conciliar el sueño al asaltarle muchos y variados pensamientos, todos relativos a su amada Dulcinea. Al querer verla como ella era antes de su encantamiento, y sabiendo de qué manera conseguirlo, toma las riendas de Rocinante y, aprovechando que Sancho está dormido, le desabrocha los calzones para empezar a azotar sus nalgas. Nada más notar un roce en sus ropas el escudero se despierta, y al saber cuáles son las intenciones de su amo, se levanta al momento para abrazarse a él e impedirle que siga adelante con su propósito: en esa postura le hace la zancadilla y lo derriba hasta dejarlo en el suelo boca arriba. Para rematar la faena le pone la rodilla derecha sobre el pecho y le inutiliza las manos con las suyas. Don Quijote no puede menos que protestar y acusar a Sancho de traidor: 
¿Cómo, traidor? ¿Contra tu amo y señor natural te desmandas? ¿Con quién te da su pan te atreves? (1117).

El hidalgo manchego se sabe víctima del pecado que Natale Conti y Pedro Sánchez de Viana habían denunciado en la fábula de Acteón. En este último episodio, más que en los anteriores, don Quijote padece la ingratitud de la persona en quien ha depositado su confianza y a quien se ha encargado de mantener, al igual que el príncipe de Tebas la había sufrido de los perros a los que había criado y alimentado (y también de sus criados y amigos que no lo reconocen tras haberse transformado en ciervo).

Después de estar una temporada en Barcelona, hospedado en casa de Antonio Moreno, el hidalgo manchego debe volver a su pueblo natal, porque se lo ha prometido al Caballero de la Blanca Luna, que no es otro que el bachiller Sansón Carrasco, al ser derrotado por él en una justa celebrada en las playas de la ciudad condal. Vencido y cansado, don Quijote desanda el camino que había seguido para llegar hasta ella, y así vuelve otra vez a pasar por el mismo lugar en que había sido atrapado por las redes de las dos pastoras. Ahora sin embargo no ve a nadie, porque es de noche, pero introduce una nueva referencia a Diana, por no vislumbrar su luz en el negro cielo de la fingida Arcadia:

Era la noche algo escura, puesto que la luna estaba en el cielo, pero no en parte que pudiese ser vista, que tal vez la señora Diana se va a pasear a los antípodas y deja los montes negros y los valles escuros (1178).

Al estar solos, el hidalgo manchego sugiere a su escudero que puede darse unos trescientos o cuatrocientos azotes a cuenta de los que debe para el desencanto de Dulcinea. Sancho se niega en rotundo, y el caballero vuelve a quejarse de su mozo, a quien trata de desagradecido:

¡Oh alma endurecida! ¡Oh escudero sin piedad! ¡Oh pan mal empleado y mercedes mal consideradas las que te he hecho y pienso de hacerte! Por mí te has visto gobernador y por mí te vees con esperanzas propincuas de ser conde o tener otro título equivalente, y no tardará el cumplimiento de ellas más de cuanto tarde en pasar este año, que yo "post tenebras spero lucem" (1179).

Al poco don Quijote y Sancho resultan atropellados por un rebaño de animales, esta vez compuesto por más de seiscientos puercos que los ganaderos que los guiaban llevaban a vender a una feria. El escudero pide a su señor la espada para matar al menos media docena de cerdos, pero el caballero andante lo disuade al estar convencido de que la afrenta que acaban de sufrir "es pena de mi pecado y justo castigo del cielo" (1181). Es ahora precisamente cuando el hidalgo manchego presenta su situación como consecuencia de la derrota que le ha infligido el Caballero de la Blanca Luna, y es también ahora cuando siente más que nunca el dolor por la ausencia de Dulcinea. 
Tras el incidente porcino, señor y escudero pasan la noche como pueden para al día siguiente reemprender el camino hacia el hogar. Por la tarde de ese día son sorprendidos por diez caballeros y cinco peones, que los llevan por la fuerza hasta el castillo de los duques, en cuyo interior descubren el cuerpo de Altisidora, aparentemente sin vida y tendido boca arriba sobre una tarima. Por ser martirizado con unos cuantos cachetes y pellizcos, Sancho consigue devolver la vida a la doncella a la que había desdeñado su señor. Desde ese momento el hidalgo manchego confía aún más en la eficacia de los azotes que su escudero debe darse para desencantar a Dulcinea, y por eso le ofrece dinero por cada uno de ellos. Sancho, pues, decide empezar a azotarse: cuando ya lleva seis u ocho azotes se detiene para pedir más dinero, $\mathrm{y}$, al concedérselo su amo, prosigue, pero lo engaña, porque, soltando de vez en cuando grandes suspiros, deja de azotarse las espaldas para azotar las cortezas de los árboles. Don Quijote no se da cuenta del engaño y, al creer que su mozo está arriesgando su vida, le pide que no la pierda, porque con ella debe sustentar a su mujer e hijos. El escudero, pues, aplaza la ejecución de los azotes que le faltan, y la lleva a cabo la noche antes de entrar en su aldea, después de haber conocido a Álvaro Tarfe, personaje de la Segunda Parte de Avellaneda, con quien su amo intercambia datos sobre la novela apócrifa.

Don Quijote está convencido de que su escudero se ha dado los tres mil y pico azotes y de que Dulcinea, en consecuencia, está desencantada, pero, en las eras de su pueblo, oye a un muchacho decir a otro que "no la has de ver en todos los días de tu vida" (1210), y el hidalgo interpreta que alude a su amada, a quien piensa que no verá ya más. Al poco se reafirma en sus sospechas al descubrir una liebre huyendo de perros y cazadores para refugiarse debajo del rucio de Sancho. Llega a su casa después de hablar con el cura y Sansón Carrasco, a quienes ha hecho saber sus intenciones de convertirse en pastor al menos durante el año que estará apartado del ejercicio de la caballería. Se siente indispuesto y se mete en su cama, donde en pocos días morirá consumido por "melancolías y desabrimientos" (1216), después de recobrar el juicio y la cordura. Desfallece en el momento en que tiene la convicción de que ha perdido ya para siempre, y de manera irremediable, a Dulcinea.

Cervantes parece haber pensado mucho el último tramo de su novela, el que va desde la salida de su personaje del castillo de los duques hasta el regreso al hogar. Ha querido que todos esos capítulos finales de su magna obra estuvieran de alguna manera presididos por la figura de Acteón, con quien don Quijote se ha comparado al sorprender a dos adolescentes disfrazadas de pastoras. En ese punto el hidalgo manchego ha recordado al príncipe de Tebas por sentirse protagonista de una situación que cree similar a la suya: la de hallarse atónito por ser testigo de una belleza sin igual (salvando, claro está, la de Dulcinea). Pero en seguida utiliza el mito evocado para aplicarlo según una explicación alegórica o moral que era nueva para la época y que contradecía la medieval. Se identifica con Acteón para denunciar un pecado que ha podido cometer, especialmente con Altisidora, pero del que pronto acabará siendo víctima: el pecado de la ingratitud. Desde ese momento padece constantes y 
duros infortunios cuando intenta agradecer, cada vez que puede, los beneficios de las personas a las que va conociendo. Así, por ejemplo, en episodios simétricos, es arrollado en dos ocasiones, pero en el mismo lugar en que descubre a las pastoras, por una manada primero de toros y después de cerdos. Se podría pensar que ése es un castigo semejante al que recibe el príncipe tebano, y en verdad lo es, porque los dos resultan agredidos por animales, aunque con desenlaces muy diferentes. ${ }^{10}$ Esos dos episodios Cervantes los introduce en relación muy directa con la doble estancia de don Quijote en el castillo de los duques: tras la primera salida y antes de la segunda entrada. En el ínterin el hidalgo manchego ha sufrido la derrota en las playas de Barcelona al enfrentarse al Caballero de la Blanca Luna, que lleva en su escudo la misma imagen que la diosa Diana llevaba en la frente, una media luna.

Antes y después de ese episodio Cervantes sitúa los episodios en que Sancho Panza demuestra su ingratitud hacia su amo primero al negarse a azotarse y después haciendo ver que se azotaba. También antes y después del episodio de la derrota de don Quijote coloca los dos episodios en que descubre las incongruencias de la Segunda Parte del Avellaneda. En todos esos episodios, en definitiva, denuncia la ingratitud de algunos personajes hacia el protagonista, y no tanto la del protagonista hacia, por ejemplo, Altisidora.

Cervantes, además, quiere que su protagonista sucumba ante un caballero que enarbola como insignia más representativa de su personalidad la media luna de Diana, la diosa de la castidad, la misma que infligió tan duro correctivo al príncipe de Tebas. De esa manera, da a entender que don Quijote ha sido vencido por un caballero aún más casto que él, pero también que el hidalgo manchego, al igual que Acteón, ha iniciado su declive por culpa de la diosa cazadora. Pero para establecer un vínculo entre personaje y mito recurre a sus moralizaciones más modernas, las que desde mediados del siglo XVI presentaban al príncipe tebano como modelo de quien era víctima de la ingratitud, y no de quien invertía más de lo necesario en la caza. En ese aspecto Cervantes, como Erasmo, evita las moralizaciones de los mitos clásicos que el humanismo había considerado absurdas y ridículas. Es sin duda un hombre más del Renacimiento que del Barroco.

10. Llegando a otro tipo de interpretación, ha visto en esos dos episodios similitudes con el castigo de Acteón Clark Colahan, "Lunar Pigs Trash Crazed Green Cultists (DQ 2, chs 58-68)", Bulletin of the Cervantes Society of America, 14, 2 (1994), pp. 71-78. 


\section{Resumen}

El presente trabajo pretende demostrar cómo Cervantes, en el Quijote, rechaza las interpretaciones medievales del mito de Acteón, según las cuales el príncipe tebano representaba los males de la caza, y se atiene a las sugeridas durante el Renacimiento, sobre todo por el manual de Natal Conti, quien cree ver en la figura del joven cazador a la víctima del pecado de la ingratitud. Precisamente en el único pasaje en que Cervantes menciona esa fábula pone en boca de su protagonista un discurso sobre la ingratitud que parece condicionar el desarrollo de la novela hasta su final.

Palabras clave: Literatura medieval y renacentista. Mitología. La fábula de Acteón. Cervantes. El Quijote.

\section{Summary}

In this work I'm trying to show how Cervantes, in El Quijote, refuses the medieval interpretation about the Acteon myth; according to them, the prince of Thebes simbolizes the danger of hunting. Cervantes follows the theories suggested in the Renaissance, mainly the ones in the book by Natal Conti, who thinks that the young hunter suffers from. For this reason, Cervantes puts up with some ungrateful characters in the only passage where he mentions this fable, and this fact sems to determine the development of the novel to the end.

Key words: Medieval and Renaissance Literature. Mythology. The Acteon's Fable. Cervantes. El Quijote. 